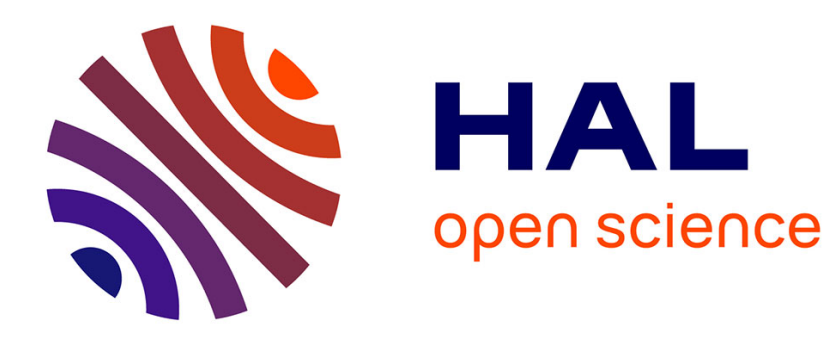

\title{
The REDD scheme to curb deforestation: a well designed system of incentives?
}

Charles C. Figuieres, Estelle Midler, Solenn S. Leplay, Sophie Thoyer

\section{To cite this version:}

Charles C. Figuieres, Estelle Midler, Solenn S. Leplay, Sophie Thoyer. The REDD scheme to curb deforestation: a well designed system of incentives?. 2010. hal-02813706

\section{HAL Id: hal-02813706 \\ https://hal.inrae.fr/hal-02813706}

Preprint submitted on 6 Jun 2020

HAL is a multi-disciplinary open access archive for the deposit and dissemination of scientific research documents, whether they are published or not. The documents may come from teaching and research institutions in France or abroad, or from public or private research centers.
L'archive ouverte pluridisciplinaire HAL, est destinée au dépôt et à la diffusion de documents scientifiques de niveau recherche, publiés ou non, émanant des établissements d'enseignement et de recherche français ou étrangers, des laboratoires publics ou privés. 


\title{
The REDD scheme to curb deforestation: An ill-defined system of incentives?
}

\begin{abstract}
The need to find a global agreement to limit deforestation has led to the REDD scheme which proposes that developed countries pay developing countries for $\mathrm{CO} 2$ emissions saved through avoided deforestation and degradation. This article describes the issues at stake and demonstrates with a stylized transfer scheme which describes the negotiation between developing countries over the allocation of the forest fund, that there is a threshold in the level of contribution from the North. Below this level, the mechanism failed to curb the deforestation. Beyond this level, the REDD scheme induces perverse effects: the larger the North's contribution, the larger the deforestation rate. Consequently, the mechanism is most effecitve only at a threshold level. Besides, it implies deforestation efforts that generally fall short of the Pareto optimal level.
\end{abstract}

\section{Preliminary version}




\section{Introduction}

Safeguarding the tropical rainforest is one of the most important challenges for the future: about 13 million hectares of forest have been cleared each year between 1990 and 2005, mostly under the pressure of logging activities and agricultural land expansion (FAO, 2005).

Tropical forests provide local public benefits for almost 750 millions of people (Chomitz, 2007), regulating local climate, quality and quantity of water in watersheds, and preserving soil fertility. But their environmental benefits extend well beyond tropical forest countries. They are the second biggest stock of carbon on earth after oceans, therefore contributing to mitigate climate change. They are also the largest hotspots of terrestrial biodiversity, sheltering between 50 and 90 per cent of the total biodiversity of the planet (WCED, 1987). Deforestation has therefore huge environmental consequences at the world level: forest clearance is now the second leading cause of carbon emissions, just behind the energy sector, and is responsible for the extinction of many species. Consequently the preservation of tropical forests became a global issue and is now a hot topic on the agenda of international environmental negotiations, especially the United Nations Framework Convention on Climate Change (UNFCCC) and the Convention on biological diversity (CBD). At stake is an agreement between developed countries (or donor countries) which are willing to contribute to an incentive scheme to reduce the global deforestation rate, and tropical forest countries (or host countries) for whom limiting deforestation has an opportunity cost in terms of agricultural production and foreign exchange earnings from wood exports.

A transfer scheme is currently under examination: the United Nations program on Reducing Emissions from Deforestation and Degradation (REDD) proposes that developed countries pay developing countries for CO2 emissions saved through avoided deforestation. The REED scheme, as defined by the 2007 Bali meeting of the UNFCCC, is thus an output-based payment, financed by donor countries, and compensating for a stock service provided by tropical forest countries. However, there is no consensus yet on the way such financial incentives should be calculated and allocated. The Bali roadmap is thus encouraging parties to explore the feasibility of various transfer mechanisms, with the view to implement REDD after 2012 in the next commitment period of the Kyoto Protocol.

Most available analysis focus on a mechanism in which the compensation is paid proportionally to the difference between the observed rate of 
deforestation and a given baseline. The goal of the present work is to analyse whether such a proposal can effectively lead to a successful outcome, in which developed countries will accept to contribute to a global fund and developing countries will lower their deforestation below an agreed rate.

The article is organized as follows. The next section gives a short historical perspective about international negotiations on deforestation and summarizes the main contributions of economic theory to the debate. Section 3 constructs a simple framework where the north-south dimension of the deforestation dilemma can be captured. That section uses this framework to investigate the logic of the REDD compensation scheme and to assess whether such mechanism can be effective. It shows that the properties of such scheme are very disappointing and can in fact lead to a non cooperative outcome without any gains in terms of avoided deforestation. The conditions under which the scheme could work are restrictive and require that countries be perfectly informed about their preferences and costs, which is not credible. The last section concludes.

\section{The genesis of REDD: a brief historical per- spective}

Developed countries have long been aware of the alarming rate at which deforestation is taking place in tropical countries and of the irreversible losses associated with the destruction of the primary forest. However, although several attempts have been made to establish a multilateral convention on forest protection, developing countries, represented by the G77, have been reluctant to make commitments which jeopardize their rights to exploit their forestry resources without compensations from the rest of the world. The 1992 Rio summit failed to launch such a convention. Since then, the only outcome of international negotiations has been the adoption of non-legally binding principles concerning sustainable forest management and trade of tropical timber.

The failure to reach a global agreement has been however partially compensated by other types of initiatives, mainly driven by biodiversity conservation concerns: there are a few examples of bilateral agreements in which a donor country finances the protection of a specific forest area in a host country; the CBD has also promoted a protected area policy, financed through the 
Global Environment Facility ${ }^{1}$. In both cases, it is a project-based approach, in which donor countries only pay for incremental costs of protection in a given area: they are willing to compensate the operational costs of conservation, as well as a proportion of foregone revenues from land uses other than conservation, for the forest protection measures that would not have been undertaken otherwise by recipient countries. Although this approach -based on the principle of additionality- supposedly satisfies the individual participation constraints of tropical forest countries, it has been limited in scope (Deke 2004), due to cumbersome control and administrative procedures and to the insufficient financial resources of the GEF which depends on voluntary contributions of developed countries.

The climate negotiations also failed to include deforestation in the 1997 Kyoto protocol. Although reforestation and afforestation projects were made eligible as carbon sinks projects and could thus be included in the Clean Development Mechanism ${ }^{2}$, the deforestation issue was left aside. The main concerns was that forestry activities would crowd-out other -longer termmitigation efforts and that leakage (the displacement of deforestation activities outside the project boundaries, without any net gan in the national deforestation rate) would be almost impossible to control and prevent.

The urgency of the climate change issue has led to the REDD proposal, tabled in March 2005 by the Rainforest Coalition in the 11th Conference of Parties of the UNFCCC.

The main innovation of REDD is to shift away from a logic of cost compensation towards a logic of purchase of $\mathrm{CO} 2$ storage service. Until then, all transfers were input-based payments, financing implementation costs of forest conservation. The REDD transfers are output-based payments: they are allocated per unit of real reduction of deforestation rate (compared to a reference rate, called the baseline) and the per-unit payment should reflect the market price of carbon emissions rather than the individual countries'

\footnotetext{
${ }^{1}$ The Global Environment Facility (GEF) is a global partnership among 178 countries, international institutions, non-governmental organizations and the private sector. It helps to finance sustainable development initiatives in the field of global environmental issues. It is also the designated financial mechanism for some multilateral environmental agreements and framework conventions.

${ }^{2}$ the Clean Development Mechanism (CDM) allows developed countries - which must satisfy emission reduction targets - to use certified emission reductions obtained by financing specific projects in developing countries. Eligible projects include emission abatement projects as well as the replanting of new forests. Forest conservation projects are excluded.
} 
conservation $\operatorname{costs}^{3}$. Moreover, in contrast to $\mathrm{CDM}$ projects, the recipient countries retain full sovereignty over how to achieve the reduction in deforestation rate. The reward could either be direct monetary transfers from a multilateral fund financed by developed countries, or could be the issuance of internationally tradable emission allowances, fungible on the Kyoto market or on a separate permit market.

The REDD proposal is currently under examination and is triggering hot debates on the best way to design the transfers and make the scheme effective. The discussions cover a wide range of issues, from the risk of non permanence of forest carbon sinks (if forests are destroyed after the payments have been made) to the recurrent problem of leakage, at the international scale $^{4}$. The most difficult issues are however to overcome free-riding by donor countries, and to find an agreement on the mode of calculation of the baseline (Tacconi, 2009). These two issues are closely interlinked. The definition of the baseline will influence decision-making in both host and donor countries, through the calculations of the transfers obtained by host countries, the size of total contributions to be made by donor countries and the net gains in terms of avoided deforestation. If host countries succeed in negotiating high baselines, they will obtain large transfers without providing much effort in terms of avoided deforestation. On the other hand, too low a baseline will deter participation by host countries (Karsenty and Pirard, 2007). Parties and research institutions have submitted different proposals for the methodology of the baseline calculation: the historical baseline would reflect past trends of deforestation rates, at the individual level or at the global level, or a mix of both; the business-as-usual (BAU) baseline would be calculated on the basis of the deforestation rate that would occur without the implementation of REDD. Whereas the latter method can end up in endless controversies about the methodology to establish predicted scenarios of deforestation, the former approach penalizes countries with low past rates of deforestation and overlooks the "forest transition' phenomenon ${ }^{5}$. Despite the numerous proposals

\footnotetext{
${ }^{3}$ Numerous research and expertise works have attempted to evaluate the unitary carbon price required to compensate the opportunity costs of avoided deforestation. Loisel (2008) makes a review of these recently published evaluations and concludes that the price of carbon credits could vary from 0.06 to 730 euros per ton of $\mathrm{CO} 2$ stored in forests.

${ }^{4}$ If several countries reduce their deforestation rates, the world market price of timber will increase, providing incentives for non signatory countries to increase logging.

${ }^{5}$ Advocates of the forest transition phenomenon argue that high rates of deforestation are only transitory and should decline with income growth, as demonstrated empirically by
} 
put on the negotiation table, no agreement has been reached on the baseline calculation method so far. The first explanation could be that countries have diverging views on the criteria that should justify international transfers: whereas some countries argue that transfers should "punish" past bad behavior, even at the expense of efficiency, others want transfer payments that deter future threats of pollution by offering greater compensation to countries with greater nuisance capacity. Another more fundamental reason is that the baseline calculation is a key element in the negotiation strategies of host countries, who are are aware that they will have to share between them the funds made available by donor countries to limit deforestation. The discussions about the baseline are to some extent comparable to a bargaining game for sharing a new resource.

In the vast theoretical literature on international environmental agreements, a few papers focus on the transfer schemes between donor countries wishing to conserve resources (such as biodiversity or tropical forest) with global public benefits, and recipient countries which have sovereignty over these resources. Donor countries - often developed countries - have to decide on their individual contributions to the multilateral fund, whereas recipient countries have to decide on their participation in the scheme and on the relative effort provided by each in the total conservation effort. The division between developed countries and developing countries of the net surplus generated by the cooperation is also at stake. Barrett (1994) focuses on the free-rider problem in the contribution game to a global biodiversity conservation fund by developed countries. He shows that when a self-enforcing full cooperative agreement is attainable, then the net benefits are small compared to the non cooperative outcome. Neumayer (2001) summarizes this finding by stating that "cooperation is either narrow (instead of wide) or shallow (instead of deep)". However, Barrett's model, like most models on international cooperation, overlooks the potentially strategic behaviour of developing countries in the transfer game. Rupert et al (2004) build a biodiversity bargaining game in which developing countries act strategically to extract more surplus from donor countries: they show that badly-designed institutions can in fact engender perverse effects which reduce biodiversity conservation instead of stimulating it.

the Kuznets curve analysis for deforestation (Koop and Tole, 1999). Thus if it is expected that the rate of deforestation decreases naturally over time (Karsenty and Pirard, 2007), this should be taken into account in the revision of the baseline to avoid unnecessary monetary compensations. 
We use a similar approach to build a stylized model of the North-South negotiation over the implementation of the REDD scheme in which the developed countries' decisions are their financial contributions to the global fund and the developing countries' strategic decisions are their individual deforestation rate and their individual baselines. We show that this mechanism can be effective, though in a very particular way defined by a specific threshold: under a given size of total contributions by the North, the mechanism has no impact of deforestation. Beyond that threshold, additional funding is counter-productive in that it increases deforestation! Overall, the present analysis does not make a strong case in favor of the REDD scheme.

\section{A simple South-North deforestation model}

Consider two countries in the developing South (labelled $i=1,2$ ) with a high endowment of forests. The North can decide to contribute to a global transfer fund which is used to pay rewards to developing countries accepting to reduce their deforestation rates under a given individual baseline. The size of the global transfer fund set by the North is known by developing countries. Let $d_{i} \in\left[0, d_{i}^{\max }\left[, i=1,2\right.\right.$, be the amount of hectare deforested, where $d_{i}^{\max }$ is the total forest area of country $i$. Let $\left(d_{1}, d_{2}\right)$ be the vector of deforestation decisions.

Countries' preferences in the South are captured by utility functions $u_{i}\left(c_{i}\right)$, defined over a composite consumption good $c_{i}$. Those utility functions are continuous, strictly increasing and concave, $u_{i}^{\prime \prime}\left(c_{i}\right) \leq 0<u_{i}^{\prime}\left(c_{i}\right)$. The composite good is produced via a technology that uses two inputs: deforestation $d_{i}$ and an initial exogenous wealth $w_{i}$ which can be increased by transfers $T_{i}$ from the North. Thus:

$$
c_{i}=f^{i}\left(d_{i}, w_{i}+T_{i}\right)
$$

Those production functions satisfy the following intuitive properties:

$$
\begin{aligned}
& f_{1}^{i}=\frac{\partial f^{i}}{\partial d_{i}}\left\{\begin{array}{l}
>0 \quad \forall d_{i} \in\left[0, \bar{d}_{i}[\right. \\
=0 \quad \forall d_{i} \in\left[\bar{d}_{i}, d_{i}^{\max }[\right.
\end{array}\right. \\
& f_{2}^{i}=\frac{\partial f^{i}}{\partial\left(w_{i}+T_{i}\right)} \geq 0,
\end{aligned}
$$




$$
f_{11}^{i}=\frac{\partial^{2} f^{i}}{\left(\partial d_{i}\right)^{2}} \leq 0, \quad f_{22}^{i}=\frac{\partial^{2} f^{i}}{\left[\partial\left(w_{i}+T_{i}\right)\right]^{2}} \leq 0 .
$$

Property (1) means that there are country-specific limits, $\bar{d}_{i}$, beyond which nature cannot be turned into arable lands; for geographical, bio-physical or economic reasons the marginal product is zero beyond those thresholds. Plugging back those technological constraints into utility functions $u_{i}$, we can redefine the cardinal representation of preferences as follows:

$$
U^{i}\left(d_{i}, w_{i}+T_{i}\right) \equiv u_{i}\left[f^{i}\left(d_{i}, w_{i}+T_{i}\right)\right]
$$

where $U^{i} \equiv u_{i} \circ f^{i}$ is non decreasing and concave with respect to both arguments. This simple model captures some of the logic underlying the North-South deforestation dilemma: southern countries can enjoy the same or perhaps a higher level of utility after limiting deforestation, provided their sacrifice is offset by a sufficient increase of the second input, i.e. by monetary transfers.

We will assume usual Inada conditions to avoid corner decisions in the domain $\left[0, d_{i}^{b}\right]$ :

\section{Condition 1}

$$
\lim _{d_{i} \rightarrow 0}\left\{U_{1}^{i}\left[d_{i}, w_{i}+t\left(d_{i}^{b}-d_{i}\right)\right]-t U_{2}^{i}\left[d_{i}, w_{i}+t\left(d_{i}^{b}-d_{i}\right)\right]\right\}>0
$$

\section{Condition 2}

$$
\lim _{d_{i} \rightarrow d_{i}^{b}, d_{i}<d_{i}^{b}}\left\{U_{1}^{i}\left[d_{i}, w_{i}+t\left(d_{i}^{b}-d_{i}\right)\right]-t U_{2}^{i}\left[d_{i}, w_{i}+t\left(d_{i}^{b}-d_{i}\right)\right]\right\}<0 .
$$

Under conditions 1 and 2 and the other assumptions made so far, there exists an interior local maximum $d_{i}^{*}$ to the utility function in the interval $\left[0, d_{i}^{b}\right]$. It will also be a global maximum when:

Condition $3 U^{i}\left(d_{i}^{*}, w_{i}+t\left(d_{i}^{b}-d_{i}^{*}\right)\right) \geq U^{i}\left(\bar{d}_{i}, w_{i}\right)$. ticular:

It is worth noting further properties about the utility functions, in par-

$$
\frac{d U^{i}\left(d_{i}, w_{i}+T_{i}\right)}{d d_{i}}=\left\{\begin{array}{cl}
u_{i}^{\prime}(.) *\left[f_{1}^{i}(., .)-t f_{2}^{i}(., .)\right] & \forall d_{i} \in\left[0, d_{i}^{b}[\right. \\
u_{i}^{\prime}(.) * f_{1}^{i}>0 & \forall d_{i} \in\left[d_{i}^{b}, \bar{d}_{i}[\right.
\end{array}\right.
$$


Condition 2 entails that the slope of the utility function is negative when $d_{i}$ approaches $d_{i}^{b}$ from below; given that this fonction has a positive slope at $d_{i}=0$ (Condition 1) and that it is concave in the interval $\left.] 0, d_{i}^{b}\right]$, necessarily there exists a value $d_{i}^{*}$ that cancels out the derivative of $U^{i}$ in the interval ] $\left.0, d_{i}^{b}\right]$. And the inequality in Condition 3 ensures that the utility computed at this interior value $d_{i}^{*}$ is larger than the utility computed at the upper corner $\bar{d}_{i}$. Then, under Conditions 1,2 and 3 country $i$ 's utility, as a function of $d_{i}$, is depicted in Figure 1 . It has a discontinuity point at $d_{i}=d_{i}^{b}$.

\section{Insert figure 1 about here}

Example 4 Utility functions could be specified as follows ${ }^{6}$ :

$$
U^{i}\left(d_{i}, w_{i}+T_{i}\right)=\alpha_{i} \log \left(d_{i}\right)+\beta_{i} \log \left(w_{i}+T_{i}\right), \quad \alpha_{i}, \beta_{i}>0 .
$$

Condition 1, in this log utility example, is automatically satisfied since

$$
\lim _{d_{i} \rightarrow 0} \frac{d U^{i}}{d d_{i}}=\frac{\alpha_{i}}{d_{i}}=+\infty
$$

Condition 2 imposes $\alpha_{i} w_{i}<\beta_{i} t d_{i}^{b}$ and Condition 3 for a global maximum reads as:

$$
\begin{aligned}
& \alpha_{i} \log \left(\frac{\alpha_{i}}{\alpha_{i}+\beta_{i}} \frac{w_{i}}{t}+\frac{\alpha_{i}}{\alpha_{i}+\beta_{i}} d_{i}^{b}\right)+\beta_{i} \log \left(\frac{\beta_{i}}{\alpha_{i}+\beta_{i}} w_{i}+\frac{\alpha_{i} t}{\alpha_{i}+\beta_{i}} d_{i}^{b}\right) \\
> & \alpha_{i} \log \left(\bar{d}_{i}\right)+\beta_{i} \log \left(w_{i}\right) .
\end{aligned}
$$

Assume schematically that developing countries are not concerned about the global level of deforestation and its impact on climate change. Accordingly in the model the global public good role of forests does not appear in utility functions of the South. Indeed, currently developing countries do not

\footnotetext{
${ }^{6}$ Getting back to the original formulation, we could assume for instance that:
}

$$
u_{i}\left(c_{i}\right)=c_{i},
$$

and

$$
f^{i}\left(d_{i}, w_{i}+T_{i}\right)=\alpha_{i} \log \left(d_{i}\right)+\beta_{i} \log \left(w_{i}+T_{i}\right), \quad \alpha_{i}, \beta_{i}>0, \quad i=1,2 .
$$


participate to the mitigation of climate change and refuse to have bindingconstraints on their emissions. So, their priority is not to preserve forests, unless they have compensations ${ }^{7}$.

The mechanism under consideration subsidizes developing countries that are willing to lower their deforestation compared to a baseline level $d_{i}^{b}<\bar{d}_{i}$. Formally:

$$
T_{i}=\left\{\begin{array}{cc}
t\left(d_{i}^{b}-d_{i}\right) & \text { if } \\
0 & \text { otherwise }
\end{array} \quad d_{i}<d_{i}^{b}\right.
$$

In the expression above, $t$ is the exogenous rate of transfer. A possibility under examination is to specify this rate as follows: $t=C D * 3.66 * P C$ where $C D$ is the carbon density $(\operatorname{ton} C / \mathrm{Ha}), 3.66$ is the atomic ratio of carbon dioxyde to carbon $\left(\operatorname{ton} \mathrm{CO}_{2} / C\right)$ and $P$ is the current price of carbon (et C, KESAKO ?). We consider that all tropical forests have the same carbon density. Clearly, when the mechanism is implemented, the baseline operates as a ceiling. The budget of the global transfer fund must balance. Therefore, if the sum of the North contributions to the fund is $e$ then:

$$
T_{1}+T_{2}=e
$$

Under the business-as-usual scenario (BAU), there is no monetary tranfers $\left(T_{1}=T_{2}=e=0\right)$ and southern countries settle for decisions $d_{i}^{N}$ implying maximal deforestation. Indeed:

$$
U_{1}^{i}\left(d_{i}, w_{i}\right)=u_{i}^{\prime}(.) f_{1}^{i}(., .)=0 \quad \Rightarrow \quad d_{i}^{N} \in\left[\bar{d}_{i}, d_{i}^{\max }[\right.
$$

The above expression means country $i$ is indifferent between any deforestation decision $d_{i}^{N} \in\left[\bar{d}_{i}, d_{i}^{\max }[\right.$, in which case we assume that it will choose to deforest no more than $\bar{d}_{i}$. The resulting global deforestation level $\bar{d}_{1}+\bar{d}_{2}$ is judged to be too high by the North, which is thus prepared to compensate the South for limiting it.

We assume that in current negotiations, northern countries will be able to raise a certain level of funds which will restrain the possibilities of action for tropical countries. This amounts to give a strong position to the North in the overall bargaining with developing countries, the later being confronted with a take-it-or-leave-it offer. The corresponding timing of decisions runs as follows: 1) the North decides upon the level of transfers $e, 2$ ) developing

\footnotetext{
${ }^{7} \mathrm{~A}$ formulation that captures this role would have $d_{j}, j \neq i$, as a third argument in the utility functions.
} 
countries bargain over the baseline knowing the size of the global transfer fund $e$ and knowing the per unit "price" for avoided deforestation $t$ and finally 3) developing countries choose independently their deforestation rates. As usual, the model is solved by backward induction.

\subsection{Deforestation decisions}

In the last decision period, developing countries maximize their utility through their choices of the level of deforestation under the REDD mechanism, knowing their baseline $d_{i}^{b}$ that has been determined in the previous period. Here, we presume that tropical countries can choose their levels of deforestation. Of course, the deforestation process results from a lot of agents' decisions and not only from public decisions. However, REDD mechanism is supported by this assumption, so we keep it. In the following, we focus on the solution $d_{i}^{*}$ of the utility maximization when $d_{i}^{*}<d_{i}^{b}$. Formally, optimal deforestation decisions then solve the first order conditions:

$$
U_{1}^{i}\left(d_{i}^{*}, w_{i}+T_{i}\right)-t U_{2}^{i}\left(d_{i}^{*}, w_{i}+T_{i}\right)=0, i=1,2 .
$$

¿From this expression, using the Implicit Function Theorem one finds:

$$
\frac{d d_{i}^{*}}{d t}=\frac{U_{2}^{i}+\left(t U_{22}^{i}-U_{12}^{i}\right)\left(d_{i}^{b}-d_{i}^{*}\right)}{U_{11}^{i}-2 t U_{12}^{i}+t^{2} U_{22}^{i}}
$$

The sign of this expression is generally - and surprisingly - ambiguous, except when the following assumption is retained:

Condition $5 U_{12}^{i}=0$.

Then we have:

$$
\frac{d d_{i}^{*}}{d t}=\frac{U_{2}^{i}+t U_{22}^{i}\left(d_{i}^{b}-d_{i}^{*}\right)}{U_{11}^{i}+t^{2} U_{22}^{i}}<0,
$$

which means that the larger the exogenous $t$, the lower the deforestation.

¿From the first order conditions one can also find:

$$
\frac{d d_{i}^{*}}{d d_{i}^{b}}=\frac{t^{2} U_{22}^{i}-t U_{12}^{i}}{U_{11}^{i}-2 t U_{12}^{i}+t^{2} U_{22}^{i}}
$$

Under Condition 5 the above expression boils down to: 


$$
\left.\frac{d d_{i}^{*}}{d d_{i}^{b}}=\frac{t^{2} U_{22}^{i}}{U_{11}^{i}+t^{2} U_{22}^{i}} \in\right] 0,1[
$$

This result indicates that country $i^{\prime}$ s deforestation increases, but less than proportionally, with the baseline level $d_{i}^{b}$ that is negotiated in the second stage.

Example 6 In the logarithmic case, individually optimal deforestation decisions solve:

$$
\begin{gathered}
\frac{\alpha_{i}}{d_{i}^{*}}-\frac{\beta_{i} t}{w_{i}+T_{i}}=0 \\
\Rightarrow d_{i}^{*}=d_{i}\left(d_{i}^{b}\right) \equiv \frac{\alpha_{i}}{\alpha_{i}+\beta_{i}} \frac{w_{i}}{t}+\frac{\alpha_{i}}{\alpha_{i}+\beta_{i}} d_{i}^{b} .
\end{gathered}
$$

At such an equilibrium:

$$
\begin{aligned}
\frac{\partial d_{i}^{*}}{\partial t}= & -\frac{\alpha_{i}}{\alpha_{i}+\beta_{i}} \frac{w_{i}}{t^{2}}<0 \\
& \text { and } \\
0 & \frac{\partial d_{i}^{*}}{\partial d_{i}^{b}}=\frac{\alpha_{i}}{\alpha_{i}+\beta_{i}}<1 .
\end{aligned}
$$

\subsection{Bargaining over the baseline in the South}

In the second period, developing countries anticipate the third period decisions described above and have been informed about the level of tranfers $e$. Whatever the chosen bargaining protocol, developing countries know they cannot collectively claim more than $e$. Hence, the outcome of the bargaining $\left(d_{1}^{b *}, d_{2}^{b *}\right)$ must belong to the following feasible set:

$$
\Omega=\left\{\left(d_{1}^{b}, d_{2}^{b}\right) / \frac{e}{t}=d_{1}^{b}+d_{2}^{b}-d_{1}^{*}-d_{2}^{*}, \quad d_{1}^{b} \leq \bar{d}_{1}, \quad d_{2}^{b} \leq \bar{d}_{2}\right\} .
$$

If developing countries fail to reach an agreement, the North will refuse to make any transfer. 
The bargaining over the baseline can be conceptualized in several ways. One could for instance refer to the Nash bargaining solution ${ }^{8}$. But for the purpose of the present paper, the exact bargaining solution need not be made precise, provided it has the property of symmetry $d_{1}^{b}=d_{2}^{b}$ (which is the case for instance of the Nash, Kalai-Smorodinsky, and Shapley solutions).

\subsection{Determination of the transfer $e$ by the North}

The North's preferences are captured by a continuous and concave utility function $U^{3}\left(d, w_{3}\right)$ which is decreasing with global deforestation $d=d_{1}+d_{2}$ and increasing with its wealth $w_{3}$.

The perspective of the present paper raises three crucial questions: $i$ ) what is the effect of the size of the global transfer fund on the endogenous baselines? more importantly, ii) what is the effect of $e$ on deforestation decisions? and finally, $i i i)$ what level of transfer will be decided by the North ?

Regarding the two first questions, the following answers can be established:

Proposition Starting from a level of transfer that sustains an interior optimum for deforestation decisions, under Condition 5 the higher the size of the global transfer fund e, the greater the agreed baselines and the larger the deforestation rates.

\footnotetext{
${ }^{8}$ To arrive at the Nash bargaining solution, define each country's indirect utility functions as follows:

$$
H^{i}\left(d_{i}^{b}\right) \equiv U^{i}\left[d_{i}\left(d_{i}^{b}\right), w_{i}+t\left(d_{i}^{b}-d_{i}\left(d_{i}^{b}\right)\right)\right] .
$$

If developing countries fail to reach an agreement, deforestation is at its maximum rate and indirect utilities are:

$$
\bar{H}^{i} \equiv U^{i}\left(\bar{d}_{i}, w_{i}\right)
$$

Assuming that the bargained outcome is given by the Nash solution, then $\left(\bar{H}^{1}, \bar{H}^{2}\right)$ play the role of threat points for country 1 and country 2 .

And $\left(\tilde{d_{1}^{b}}, \tilde{d_{2}^{b}}\right)$ solve:

$$
\max _{\left(d_{1}^{b}, d_{2}^{b}\right) \in \Omega}\left[\left(H^{1}\left(d_{1}^{b}\right)-\bar{H}^{1}\right]\left[H^{2}\left(d_{2}^{b}\right)-\bar{H}^{2}\right],\right.
$$
}

where $\Omega$ represents the feasible set of baseline decisions given by (4) in the text. 
Proof. Since we have $\frac{e}{t}=d_{1}^{b}+d_{2}^{b}-d_{1}\left(d_{1}^{b}\right)-d_{2}\left(d_{2}^{b}\right)$, differenciating by $e$, $d_{1}^{b}$ and $d_{2}^{b}$ gives us:

$$
\frac{d e}{t}=\left(1-\frac{\partial d_{1}}{\partial d_{1}^{b}}\right) d d_{1}^{b}+\left(1-\frac{\partial d_{2}}{\partial d_{2}^{b}}\right) d d_{2}^{b}
$$

Because the bargaining outcome satisfies symmetry, we have $d d_{1}^{b}=d d_{2}^{b}$ and therefore:

$$
\frac{d d_{1}^{b}}{d e}=\frac{1}{2 t\left(1-\frac{\partial d_{1}}{\partial d_{1}^{b}}\right)} \geq 0
$$

And finally:

$$
\frac{d d_{1}}{d e}=\frac{\partial d_{1}}{\partial d_{1}^{b}} \frac{d d_{1}^{b}}{d e} \geq 0
$$

The same reasoning applies to the second decision variable, $d_{2}$, which completes the proof.

Example 7 With the particular logarithmic case where utility functions in both tropical countries are the same $\left(\alpha_{1}=\alpha_{2}=\alpha\right.$ and $\left.\beta_{1}=\beta_{2}=\beta\right)$, one finds:

$$
\frac{d d_{i}}{d e}=\frac{\alpha}{\alpha+\beta} \frac{d d_{i}^{b}}{d e}>0
$$

Therefore, under the assumptions made so far, an increase in the total contributions from the North to the global fund increases the level of deforestation chosen by developing countries! The mechanism implements a wrong incentive program: instead of fostering deforestation reduction, it induces developing countries to increase their level of deforestation and still gain positive transfers. This result, striking at first sight, is rather intuitive upon reflection. An increase in the size of the global fund is matched by an increase in negotiated baselines because developing countries interpret it as a greater pie to share. This leaves room for an increase of deforestation, provided it is not too large compared to the increment of the baseline, in order to get a strictly positive transfer $T_{1}$. Expression (5) along with (3) shows that this is the case because $0<\frac{\partial d_{1}}{\partial e}<\frac{\partial d_{1}^{b}}{\partial e}$. To put it another way, 
there is a pernicious effect that stems from the endogenous adjustment of the baselines.

As regards contributions to the global transfer fund, the North therefore has incentives to downsize them in order to limit the temptation by developing countries to negotiate higher baselines. From the above proposition, this will reduce the baselines and the optimal deforestation decisions in the South. The utility levels attained in the South at the negotiated baselines will also be reduced. Therefore, there may exist a specific level of contributions $e^{*}$, the corresponding baselines $\left(d_{1}^{b *}, d_{2}^{b *}\right)$ and deforestation rates $\left(d_{1}^{*}, d_{2}^{*}\right)$, such that for any lower size of the global transfer fund, developing countries will prefer to give up transfers and will choose their maximal deforestation rates. These specific baselines are those that just meet Condition 3; they equalize the utility level at an interior solution with the utility level at the upper corner (see Figures 2 and 3). They are defined as the solution to:

$$
\bar{U}^{i}=U^{i}\left[\bar{d}_{i}, w_{i}\right]=U^{i}\left[d_{i}^{*}, w_{i}+t\left(d_{i}^{b *}-d_{i}^{*}\right)\right], \quad i=1,2
$$

Example 8 In the logarithmic example:

$$
\begin{aligned}
\alpha_{i} \log \left(\bar{d}_{i}\right)+\beta_{i} \log \left(w_{i}\right)= & \alpha_{i} \log \left(\frac{\alpha_{i}}{\alpha_{i}+\beta_{i}} \frac{w_{i}}{t}+\frac{\alpha_{i}}{\alpha_{i}+\beta_{i}} d_{i}^{b *}\right) \\
& +\beta_{i} \log \left(\frac{\beta_{i}}{\alpha_{i}+\beta_{i}} w_{i}+\frac{\alpha_{i} t}{\alpha_{i}+\beta_{i}} d_{i}^{b *}\right) .
\end{aligned}
$$

With those threshold baselines $\left(d_{1}^{b *}, d_{2}^{b *}\right)$ and deforestation rates $\left(d_{1}^{*}, d_{2}^{*}\right)$, one can compute the corresponding total monetary transfers $e^{*}$ from the North:

$$
e^{*}=t\left[d_{1}^{b *}-d_{1}^{*}+d_{2}^{b *}-d_{2}^{*}\right] .
$$

What the analysis of the present paper reveals is that there is no point for the North to offer contributions larger than $e^{*}$, for this will increase deforestation (and will cost more). Should it provide a smaller transfer fund than $e^{*}$, given that deforestation levels in the South would then rocket to their maximum levels? The answer depends on the comparison of the North's utility levels achieved at $e=e^{*}$ and $e=0$. To summarize:

Proposition Under Conditions 1-5 the transfer offered by the North is

$$
e^{* *}=\left\{\begin{array}{cc}
e^{*} \quad \text { if } \quad U^{3}\left(d^{*}, w_{3}-e^{*}\right) \geq U^{3}\left(\bar{d}, w_{3}\right) \\
0 \quad \text { otherwise }
\end{array}\right.
$$


In practice, identifying the threshold $e^{*}$ is no simple matter, in particular because it depends on utility parameters which are not readily observable. Differently stated, the mechanism is either ineffective, or it implies a waste of resources, except at $e^{*}$.

\subsection{Welfare properties of the REDD mechanism}

The REDD mechanism is designed to reduce deforestation to mitigate climate change. However it could be interesting to analyze this North-South transfer in terms of social welfare: maybe it helps to reduce deforestation but also damages welfare. A first interesting property is worth noting:

Proposition When the mechanism is effective, i.e. when $e^{* *}=e^{*}$, it is Pareto improving compared to the BAU scenario.

Proof. As seen in the previous section, the North offers transfers only at the condition that its utility is increased, and southern countries cut down deforestation only at the same condition.

A more ambitious goal would be to achieve Pareto optimality while improving welfare for each country. Pareto optimal deforestation decisions $d_{1}^{P O}$ and $d_{2}^{P O}$ and wealth allocations $m_{1}, m_{2}$ and $m_{3}$ would maximize a welfare function like:

$$
\sigma_{1} U^{1}\left(d_{1}, m_{1}\right)+\sigma_{2} U^{2}\left(d_{2}, m_{2}\right)+\sigma_{3} U^{3}\left(d_{1}+d_{2}, m_{3}\right),
$$

$\left(\sigma_{1}, \sigma_{2}, \sigma_{3}\right) \in \Re_{+}^{3}, \sigma_{1}+\sigma_{2}+\sigma_{3}=1$, where $m_{1}=w_{1}+T_{1}, m_{2}=w_{2}+T_{2}$ and $m_{3}=w_{3}-e$ which means that $m_{i}$ is the financial endowment of country $i$ after the transfer. The above problem gives four first-order conditions:

$$
\begin{aligned}
& \sigma_{1} U_{1}^{1}\left(d_{1}, m_{1}\right)+\sigma_{3} U_{1}^{3}\left(d_{1}+d_{2}, m_{3}\right)=0 \\
& \sigma_{2} U_{1}^{2}\left(d_{2}, m_{2}\right)+\sigma_{3} U_{1}^{3}\left(d_{1}+d_{2}, m_{3}\right)=0 \\
& \sigma_{1} U_{2}^{1}\left(d_{1}, m_{1}\right)-\sigma_{3} U_{2}^{3}\left(d_{1}+d_{2}, m_{3}\right)=0 \\
& \sigma_{2} U_{2}^{2}\left(d_{2}, m_{2}\right)-\sigma_{3} U_{2}^{3}\left(d_{1}+d_{2}, m_{3}\right)=0
\end{aligned}
$$

Since non cooperative decisions are given by equation 1 :

$$
U_{1}^{i}\left(d_{i}, w_{i}+T_{i}\right)-t U_{2}^{i}\left(d_{i}, w_{i}+T_{i}\right)=0, i=1,2,
$$


Pareto optimality of the Nash equilibrium requires that parameter $t$ solves:

$$
t=-\frac{\sigma_{3} U_{1}^{3}\left(d_{1}^{P O}+d_{2}^{P O}, m_{3}^{P O}\right)}{\sigma_{1} U_{2}^{1}\left(d_{1}^{P O}, m_{1}^{P O}\right)}=-\frac{\sigma_{3} U_{1}^{3}\left(d_{1}^{P O}+d_{2}^{P O}, m_{3}^{P O}\right)}{\sigma_{2} U_{2}^{2}\left(d_{2}^{P O}, m_{2}^{P O}\right)}
$$

a condition which means that only those Pareto optima that respect:

$$
\frac{\sigma_{1}}{\sigma_{2}}=\frac{U_{2}^{2}\left(d_{2}^{P O}, m_{2}^{P O}\right)}{U_{2}^{1}\left(d_{1}^{P O}, m_{1}^{P O}\right)}
$$

could be achieved, in theory, by the REDD mechanism.

The optimal value of $t$ depends on the fundamentals of the economy, in particular the pieces of information conveyed by preferences. The Pareto optimality of the REDD mechanism is therefore a fragile property, because it rests on subjective attributes that cannot be observed. Besides, as explained earlier the suggested value of $t$ is determined by other factors: the carbon density, the atomic ratio of carbon dioxyde to carbon, and the current price of carbon. The suggested value of $t$ has no reason to be the optimal value. Actually, it is possible that both countries reach a deforestation rate smaller or higher than the one which is Pareto-optimal. It is also possible that one of them achieves a deforestation rate smaller than the Pareto-optimal level and the other one reaches deforestation rate higher than the optimal one. The example below illustrates those possibilities.

Example 9 with logarithmic utility functions in the South, and choosing preference parameters $\alpha_{1}=\beta_{1}=\alpha_{2}=\beta_{2}$, we can find the $d_{1}^{b *}$ and $d_{2}^{b *}$ that will emerge from the mechanism. To find $d_{1}^{b *}$ we use the fact that:

$$
\log \left(\bar{d}_{i}\right)+\log \left(w_{i}\right)=\log \left(\frac{w_{i}}{2 t}+\frac{d_{i}^{b *}}{2}\right)+\log \left(\frac{w_{i}}{2}+\frac{t d_{i}^{b *}}{2}\right) .
$$

It gives us $d_{1}^{*}$ and $d_{2}^{*}$ the deforestation levels of countries 1 and 2 when the North contributes $e^{*}$ :

$$
d_{1}^{*}=\sqrt{\frac{\bar{d}_{1} w_{1}}{t}}
$$

The same reasonning applies to $d_{2}$ and so:

$$
d_{2}^{*}=\sqrt{\frac{\bar{d}_{2} w_{2}}{t}}
$$


We impose $t<\frac{w_{i}}{\overline{d_{i}}}$ to ensure that $d_{i}^{*}<\overline{d_{i}}, i=1,2$. As for the North's utility function, let us assume it takes the quadratic form:

$$
U^{3}(d, e)=-a d-\frac{b}{2} d^{2}-c e-\frac{f}{2} e^{2}, \quad a, b, c, f \in \Re
$$

With all those specifications, maximizing the welfare function 4 yields the Pareto optimal levels of deforestation:

$$
d_{1}^{P O}=\sqrt{\frac{\sigma_{1} \alpha_{1} a}{2 b}}, \quad d_{2}^{P O}=\sqrt{\frac{\sigma_{2} \alpha_{2} a}{2 b}} .
$$

Paremeters are restricted so that $d_{1}^{P O}<\overline{d_{1}}$ and $d_{2}^{P O}<\overline{d_{2}}$. If the mechanism is to implement Pareto optimal deforestation decisions, necessarily then:

$$
t=t_{1}^{P O}=\frac{2 b \bar{d}_{1} w_{1}}{\sigma_{1} \alpha_{1} a} \text { and } t=t_{2}^{P O}=\frac{2 b \bar{d}_{2} w_{2}}{\sigma_{2} \alpha_{2} a}
$$

which requires that $\bar{d}_{1} w_{1} \sigma u_{2} \alpha_{2}=\bar{d}_{2} w_{2} \sigma u_{1} \alpha_{1}$. Moreover:

$$
t \gtrless t_{i}^{P O} \quad \Leftrightarrow \quad d_{i}^{*} \lessgtr d_{i}^{P O}
$$

\section{Conclusion}

This stylised model shows that a transfer mechanism based on an endogenous baseline chosen on the amount of the trasnfer from the North can engender perverse incentives. Indeed, the mecanism leads to reduce the rate of deforestation of developing countries below their threat point, but the it creates incentives for developing countries to negotiate greater baselines, therefore allowing them potentially to both increase their deforestation rates and obtain positive transfers. Of course, the outcome of such scheme should be the refusal of developed countries to contribute significantly to the global transfer fund. This result is independent of the preference and the relative bargaining power of developing countries. It raises serious concerns about the efficiency of the REDD mechanism and its capacity to sustain a cooperative outcome. It provides arguments therefore to conduct a more careful analysis of the way the negotiation is conducted during the different decision phases of the REDD implementation, namely: the rules under which contributions 
by developed countries to the global forest fund will be calculated; the negotiations over the rules defining the baseline calculations. The baseline must be decided regardless the amount of the funds provide by the North.

Of course this result is related to our modelling choice. The strongest assumption in this model is that developing countries negotiate over their respective baselines without any intervention from the North. This can seem hardly credible in the first place. However, the on-going discussions over the REDD scheme tend to confirm this modelling option: if the international community succeeds in creating a global transfer fund for the financing of REDD, rules will be established to decide upon the Northern countries' contributions. Developing countries will then be able to assess the size of this fund and they will negotiate over the sharing rules of these new financial resources. It is not unreasonable to assume that the main driver of the negotiation will be to obtain the largest potential share of the fund, and that developed countries won't have much influence in the negotiation (except by establishing the credible threat of not creating the fund) even if, as emphasized in section 2, rules can be justified by ethical, historical or efficiency criteria. This is already revealed by the strategic positions of Brazil and Indonesia, two large deforesting countries defending the adoption of an historical baseline system, as opposed to the positions of Costa Rica and countries of the Congo Basin, with past moderate deforestation rates, defending a BAU baseline.

This paper has chosen to model the REDD scheme as based on direct monetary transfers but results would be identical if transfers were made in the form of tradable permits, since the main limitation of the proposed scheme is the baseline system. We therefore suggest that an alternative system of transfer be examined which could be based on a transfer dependent of a global deforestation rate 


\section{References}

[1] Barrett S. (1994): "The Biodiversity Supergame", Environmental and Resource Economics, 4, 111-122.

[2] Chomitz K.M., P. Buys, G. De Luca, T.S. Thomas and S. WertzKanounnikofF (2007): "At Loggerheads? Agricultural expansion, poverty Reduction, and Environment in Tropical Forests", The International Bank for Reconstruction and Development - the World Bank.

[3] Deke O. (2004): "Financing National Protected Area Networks Internationally - The Global Environment Facility as a Multilateral Mechanism Transfer", Kiel Working Paper 1227, Kiel Institute for World Economics.

[4] Food and Agriculture Organization of the United Nations, 2005, "Global Forest Resources Assessment", FAO forestry paper 147.

[5] Karsenty A. and R. Pirard (2007): "Changement climatique : fautil récompenser la déforestation évitée ?", Natures Sciences Sociétés 15, 357-369.

[6] KaRsenty A. (2008): "The architecture of proposed REDD schemes after Bali: facing critical choices", International Forestry Review, 10 (3): $443-457$

[7] Koop G. and Tole L. (1999): "Is There an Environmental Kuznets Curve for Deforestation?", Journal of Land Economics, 58: 231-244.

[8] Neumayer E. (2001): "How Regime Theory and the Economic Theory of International Environmental Cooperation Can Learn from Each Other?" Global Environmental Economics, 1 (1), 122-147

[9] Rupert J., Gatti J., Goeschl, T., Groom B. and Swanson T. (2004): "The biodiversity bargaining problem", Cambridge Working Papers in Economics WCPE 0047, 30 pages

[10] Tacconi L. (2009): "Compensated successful efforts for avoided deforestation vs compensated reductions", Ecological economics, in press.

[11] World Commission on Environment an Development, 1987, "Our common future", Oxford University Press, Oxford. 


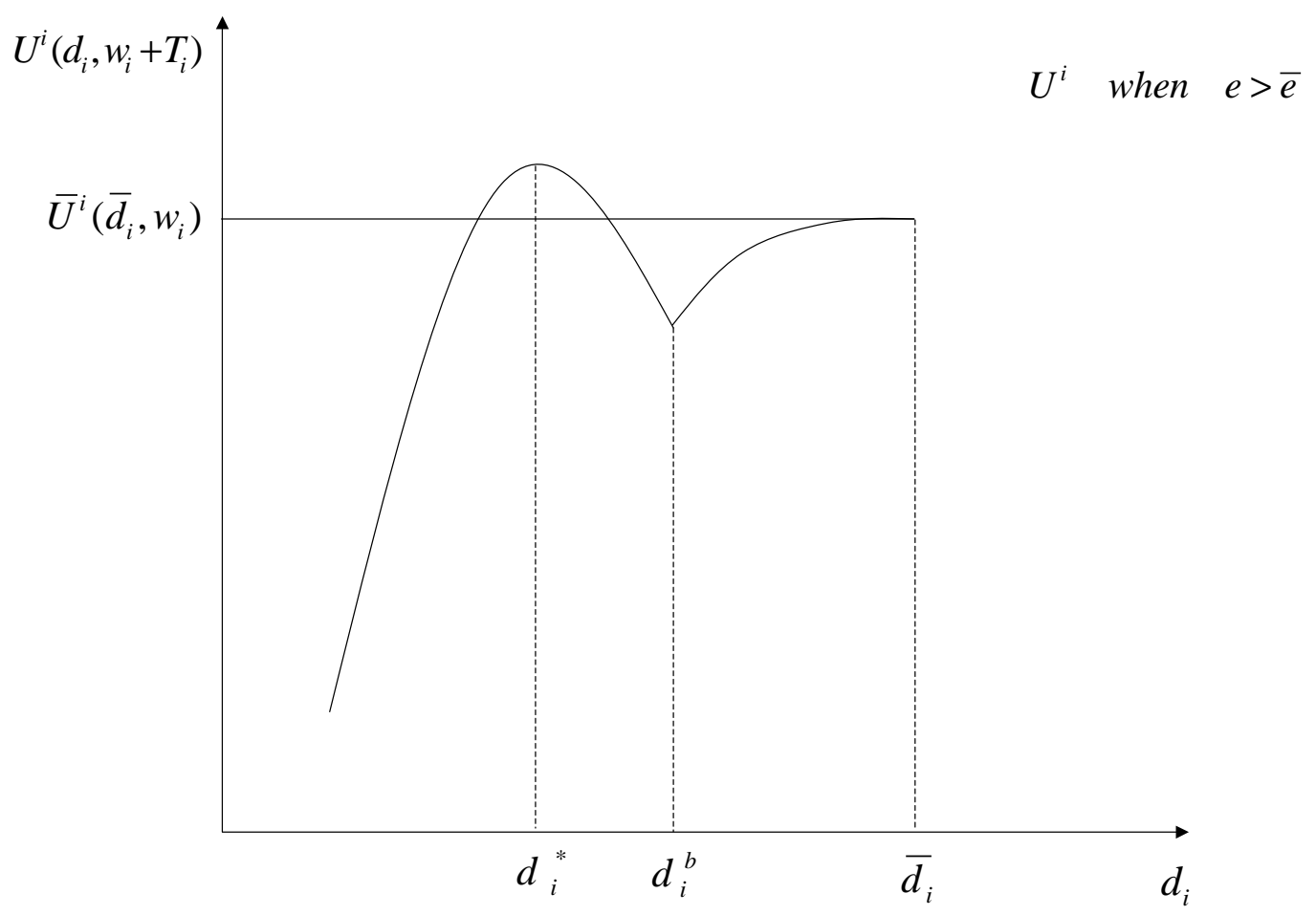

Figure 1: Utility Function 


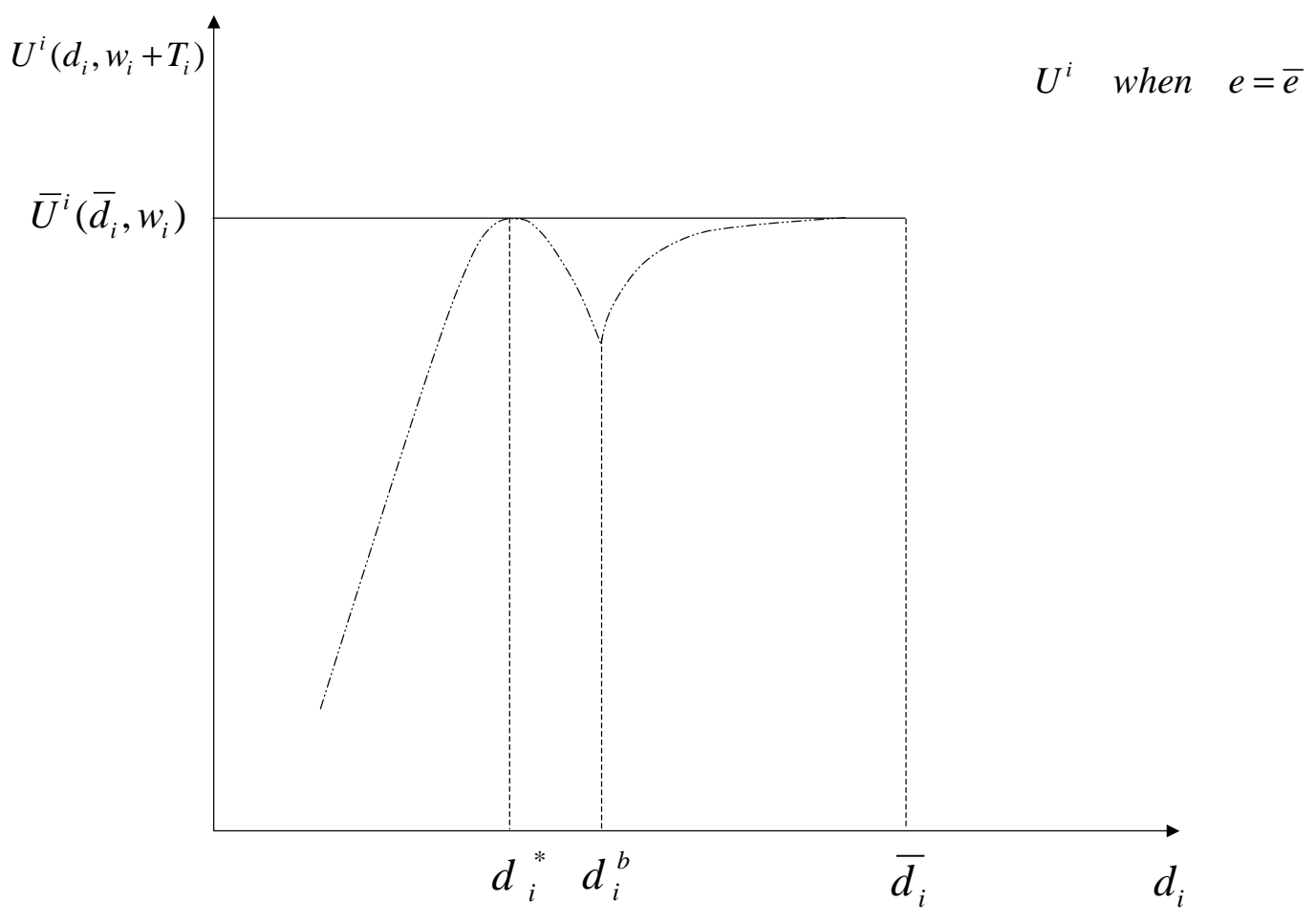

Figure 2: Utility Function when $e=\bar{e}$ 


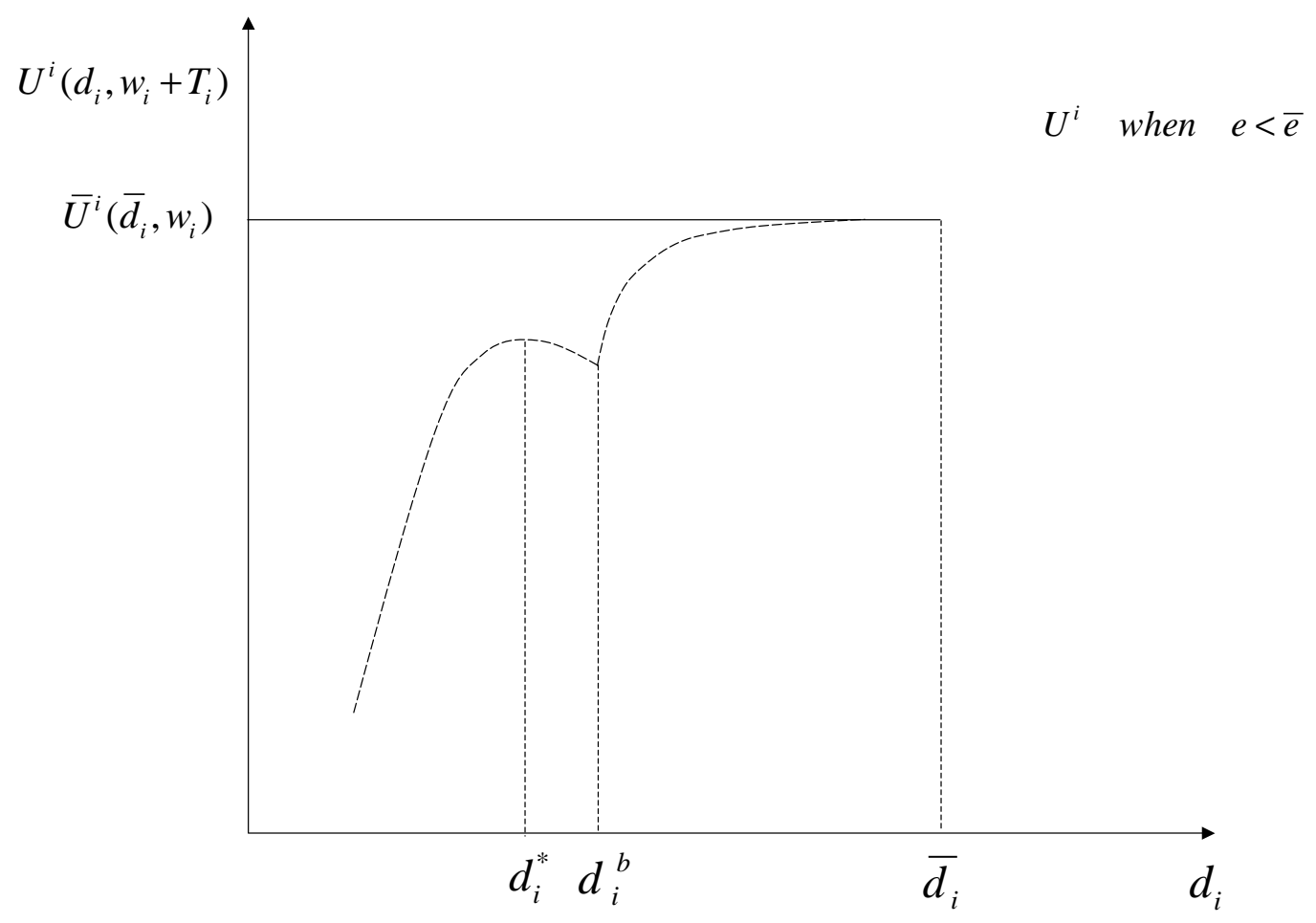

Figure 3: Utility Function when $e<\bar{e}$ 